\title{
With or Without them: Essential Roles of Cofactors in ES Cells
}

\section{Hui Ma" ${ }^{1 \#}$ Jin Rong Ow" ${ }^{1 \#}$ Xi Chen ${ }^{2 *}$ and Qiang $\mathbf{W u}^{1 *}$}

${ }^{1}$ Department of Biochemistry, Yong Loo Lin School of Medicine, National University of Singapore, 8 Medical Drive, Singapore 117597

${ }^{2}$ Department of Immunology and Infectious Diseases, Harvard School of Public Health, Boston, Massachusetts 02115, USA

\#Equally contributed

\begin{abstract}
Embryonic stem cells (ESCs) are pluripotent cells which are capable of differentiating into many cell types. A complex transcriptional network consisting of Oct4, Sox2 and Nanog maintains ESCs in undifferentiated state while being poised to be directed into different committed cell types. Recently, tremendous efforts have been made to elucidate the functions of cofactors in ESC identity and differentiation. More and more evidence has shown that cofactors are crucial for both pluripotency maintenance and differentiation capacity in ESCs. Cofactors do not bind to DNA directly. Rather, they are usually recruited to target sites by transcription factors or epigenetic marks. Transcriptional cofactors including coactivators or corepressors serve as critical components of the regulatory circuitry that ensures unique gene expression program in ESCs. In this review, we will highlight recent findings on the functions of transcriptional cofactors and the underlying molecular mechanism that maintains ESC identity.
\end{abstract}

Keywords: Cofactors; ESCs; ES cell identity; Coactivator; Corepressor; Mediator

\section{Introduction}

Embryonic stem cells (ESCs) are derived from the inner cell mass (ICM) of the blastocyst-stage embryos [1,2]. They are characterized by pluripotency and self-renewal. Hence, ESCs provide a good in vitro system for the study of early embryonic development and molecular pathways involved in pluripotency and differentiation. Additionally, by understanding how ESCs can be manipulated to differentiate into specific cell types, ESCs also have great promise in regenerative medicine and gene therapy $[3,4]$.

A complex transcriptional regulation network consisting of Oct4, Sox2, Nanog and epigenetic modifications have been known to be crucial in maintaining ESC identity [5,6]. Genome-wide studies have discovered that master regulators Oct4, Sox2 and Nanog act in cooperation by co-occupying two sets of genes: genes involved in pluripotency and genes associated with development [6-10]. They maintain ESC identity by activating transcription of pluripotencyassociated genes via recruitment of co-activators such as p300, chromatin remodelling complexes and the transcriptional machinery $[9,11,12]$, while repressing developmental regulators by engaging Polycomb (PcG) complexes as well as other co-repressor complexes, including NuRD, Sin3A and Pml complexes [11-15]. In addition, from protein-protein interactome studies, many transcriptional cofactors have been identified as binding partners of Oct4 and Nanog $[11,12,16,17]$, highlighting the importance of transcriptional cofactors in the core transcriptional network in ESCs. Transcriptional cofactors do not have DNA sequence-specific binding abilities, and hence are usually recruited to target sites by transcription factors or epigenetic marks. Transcriptional cofactors can be co-activators or co-repressors, depending on their effect on transcription, and can act through a variety of mechanisms such as histone modification, nucleosome remodelling, or recruitment of transcriptional machinery. It has well been established that activators and repressors serve as critical components of the regulatory circuitry that ensures accurate transcription of a given gene according to the needs of a particular cell [18]. Since ESCs have a unique transcriptional network which maintains their undifferentiated state while keeping them poised to differentiate into all specific lineages, studying the roles of cofactors in ESC-specific transcription regulation is of great interest. Recently, tremendous efforts have been made to elucidate the functions of cofactors in ESC identity and differentiation.
In this review, we will highlight recent findings on the functions of transcriptional cofactors and the underlying molecular mechanism that maintain ESC identity.

\section{Coactivators}

\section{Histone acetyltransferase complexes}

Many coactivators have histone acetyltransferase (HAT) activity to create decondensed chromatin structure, thus facilitating the recruitment of transcriptional machinery and other regulatory proteins to activate transcription [19]. The p300/CBP complex and Tip60-p400 have been discovered as important factors in ES pluripotency and differentiation.

p300/CBP complex: The coactivators CREB-binding protein (CBP) and p300 are closely related functional homologs, which act together in histone acetylation and non-histone acetylation [20]. The p300/CBP coactivator complex has been shown to be crucial in cell growth, transformation and development [20]. Interestingly, p300depleted ESCs show no defects in self-renewal [21], which may be credited to its functional redundancy with CBP. Silencing of both $p 300$ and $C B P$ in ESCs would provide further insights into the functional roles of this complex. However, $p 300$ can modulate Nanog expression, possibly through histone modifications at the regulatory region of Nanog [21]. On the other hand, forced expression of p300 promotes neural differentiation of ESCs [22], suggesting the involvement of p300/ $\mathrm{CBP}$ in differentiation. Indeed, multiple studies have revealed that $\mathrm{p} 300 /$ CBP mediates the activation of lineage genes during the differentiation

*Corresponding authors: Xi Chen, Department of Immunology and Infectious Diseases, Harvard School of Public Health, Boston, Massachusetts 02115, USA, Tel: 1-617-432-4080; Fax: 1-617-432-0084; E-mail: xichen@hsph.harvard.edu

Qiang Wu, Department of Biochemistry, Yong Loo Lin School of Medicine, National University of Singapore, 8 Medical Drive, Singapore 117597, Tel: (65) 65163159; Fax: (65) 67791453; E-mail: bchwq@nus.edu.sg

Received May 24, 2012; Accepted June 27, 2012; Published June 29, 2012

Citation: Ma H, Ow JR, Chen X, Wu Q (2012) With or Without them: Essential Roles of Cofactors in ES Cells. J Stem Cell Res Ther S10:006. doi:10.4172/21577633.S10-006

Copyright: (c) $2012 \mathrm{Ma} \mathrm{H}$, et al. This is an open-access article distributed under the terms of the Creative Commons Attribution License, which permits unrestricted use, distribution, and reproduction in any medium, provided the original author and source are credited. 
of ESCs into neurons, skeletal muscles and cardiac myocytes [22-27]. A recent study proposed a model in which phosphorylation of $\mathrm{p} 300$ drives the switch from $\mathrm{Wnt} / \beta$-catenin/CBP-mediated transcription to $\mathrm{Wnt} / \beta$-catenin $/ \mathrm{p} 300$-mediated transcription, and initiates the differentiation of mouse ESCs [28]. Importantly, genome-wide mapping of p300 binding sites has shown that p300, usually associated with the H3K4me3 mark, is recruited to stem cell-specific enhancers by Oct4, Sox 2 and Nanog. This suggests that p300 is an important component of the ESC transcription factor network [9]. Another study showed that p300 co-localizes and interacts with the chromatin remodeler CHD7, thus fine-tuning gene expression levels in ES cells [29].

Tip60-p400: Tip60-p400 is a multi-subunit remodeling complex possessing both histone acetyltransferase and chromatin-remodeling activities [30]. The complex consists of two core catalytic components, Tip60 and p400, and knocking out either of them causes embryonic death before implantation [31-33]. Tip60-p400 is found to interact with Oct4 [12], and knock-down of Tip60-p400 complex subunits affects ESC identity, with phenotypes including altered cell morphology, decreased proliferation rates, reduced alkaline phosphatase activity and defects in teratoma formation [34]. In addition, Tip60-p400 colocalizes with histone H3K4me3 and largely shares targets with Nanog [34]. These raise the possibility that Tip600-p400 can maintain ESCs in an undifferentiated state by cooperation with H3K4me3 or Nanog [34]. Although histone acetylation is usually a mark for active transcription, the observation that Tip60-p400 acetylates histone H4 not only at active promoters, but also at many PcG complex-occupied genes in undifferentiated ESCs indicates an additional repressive activity of Tip60-p400 in transcription regulation through some unknown mechanisms [35]. Taken together, Tip60-p400 likely possesses dual regulatory functions to maintain the balance between pluripotency and differentiation in ESCs.

\section{Yes-associated protein (Yap)}

First discovered as an interacting partner of Yes tyrosine kinase [36], YAP was found to be involved in establishing trophectodermal fate during the pre-implantation blastocyst stage [37-38]. The importance of YAP in maintaining ESC identity was recently revealed when YAP over-expression inhibited ESC differentiation [39]. YAP was suggested to act downstream of Yes, which in turn was activated by LIF [40], and together with TEAD2, activates the expression of pluripotency genes, including the master regulators Oct4 and Nanog as well as their target genes $[39,41]$. While the exact mechanism by which YAP functions as a co-activator has yet to be elucidated, it appears that YAP-TEAD2 complex can be integrated into the functional regulatory network in ESCs.

\section{Oct4-associated DNA repair proteins}

MutS homolog (MSH) 2 and MSH6 form heterodimers that bind DNA mismatches [42-45] and are part of the DNA mismatch repair mechanism [46]. In recent protein-protein interactome studies in ESCs, hMSH2 and hMSH6 were recognized as Oct4-interacting partners $[11,12,17]$. Though it is not clear if this interaction is a result of a yet unknown role of Oct4 in DNA repair, the hMSH2-hMSH6 dimer may function as a "sliding clamp" that disassembles histone octamers, in a method aided by histone acetylation [45]. Given that the hMSH2hMSH6 dimer binds DNA mismatches more efficiently than DNA without mismatches [42-45], it can be speculated that Oct4 may recruit the hMSH2-hMSH6 dimer to non-mismatched DNA for its nucleosome remodelling function and transcriptional regulation.

A stem cell coactivator complex (SCC) formed by nucleotide excision repair (NER) proteins XPC, RAD23B and CETN2 were recently discovered as a coactivator which is directly recruited by Oct 4 and Sox2 [47]. SCC is located to the Nanog and Oct4 promoters as well as a majority of genomic regions that are occupied by Oct4 and Sox2. Depletion of SCC/XPC compromises both pluripotency in ES cells and somatic cell reprogramming [47]. This function does not require the DNA-binding ability normally required for the DNA repair activity [47]. In addition, multiple NER proteins, including XPC, XPA, and XPG, were found to be involved in mediating transcription, possibly by regulating histone modifications, such as histone H3K4 methylation and $\mathrm{H} 3 \mathrm{~K} 9$ and $\mathrm{H} 3 \mathrm{~K} 14$ acetylation that are marks of active transcription [48].

\section{FACT complex}

The FACT (facilitates chromatin transcription) complex, first found to be essential for in vitro transcription [49], is involved in many aspects of transcriptional regulation and histone disassembly [50-53]. FACT consists of two subunits: SPT16 and SSRP1 [54]. SSRP1 was found to be essential for the formation of ICM in early embryogenesis [55]. Both SPT16 and SSRP1 can interact with Oct4 in ESCs [11,17]. SSRP1 also binds c-Myc [56], which is another factor that is important for ESC identity $[57,58]$. While the precise function of the FACT complex in ESCs and its role in pluripotency has yet to be determined experimentally, it can be speculated that Oct4 and c-Myc may engage the FACT complex, which in turn mediates the transcriptional regulation activities of Oct4 and c-Myc.

\section{Corepressors}

\section{Sin $3 \mathrm{a} / \mathrm{HDAC}$ complex}

Sin3a, which binds to class I HDACs HDAC1 and HDAC2, is associated with multiple repressors through its paired amphipathic helix (PAH) domains, thus recruiting HDAC activity to target promoters in transcription repression [59-63]. The Sin3a/HDAC complex is involved in maintaining cell proliferation potential, DNA repair, and termination of cell differentiation [64-66]. Sin3a-mediated repression has critical roles in diverse developmental pathways (as reviewed in [67]), and $\operatorname{Sin} 3 a$ knock-out mouse embryos die between E3.5 and E6.5 due to impaired ICM and trophectoderm formation [64,65,68].

The Sin3a/HDAC complex is essential for the proliferation, viability, and genomic integrity of pluripotent ESCs [34,68]. However, the underlying mechanisms have not been studied in detail. In ESCs, Sin $3 a$ is found to be associated with cell cycle control and DNA damage response proteins, which might contribute to the cell cycle misregulation and apoptosis observed in Sin3a-null ESCs [68]. Besides, the Sin3a/HDAC complex can positively regulate Nanog expression, possibly through interactions with Sox 2 or Nanog itself $[15,69]$. The fact that Sin3a stimulates Nanog expression might indicate a transcription activation role in ESC pluripotency regulation in the form of alternate co-repressor complexes [70].

\section{NuRD complex}

Nucleosome remodeling deacetylase (NuRD) complex couples ATP-dependent chromatin remodeling component Mi2 $\beta$ and class I histone deacetylase $\mathrm{HDAC} 1$ and $\mathrm{HDAC} 2$ to induce repressive chromatin structure [71]. Mbd3, a core component of NuRD complex, is essential for mouse early embryogenesis, and is required for the derivation of mature epiblast from the ICM, as well as the acquisition of the pluripotent ESC state $[72,73]$. Mbd3 is indispensable for stable formation of the NuRD complex - ESCs lacking $M b d 3$ are viable and 
maintain expression of Pouff1 and Nanog, but are unable to exit selfrenewal and fail to commit to developmental lineages during ESC differentiation [74]. Moreover, it is reported that Mbd3 represses preimplantation genes, such as Pramel6, and also trophectoderm-specific genes, such that loss of Mbd3 induces ESCs to differentiate towards trophectoderm lineage $[15,75]$. Thus Mbd3 is essential for the full differentiation competency of ESCs. Furthermore, a recent study has reported that $\mathrm{Mbd} 3$ is essential for transcriptional heterogeneity and the dynamic range of a set of pluripotency genes in ESCs [76].

Moreover, Mbd3 also physically interacts with Brg1, a SWI/SNF component associated with active transcription, to antagonistically regulate a group of common target genes [77,78]. Mbd3-mediated deacetylation of histone H3K27 facilitates recruitment of PcG Complex 2 (PRC2), which subsequently stimulates H3K27me3 and enables the silencing of specific genes in ESCs [76]. Considering that there is some evidence to show that the NuRD and PcG complexes interact, these two complexes may act together to reinforce a gene silencing effect $[79,80]$. It is noteworthy that $\mathrm{Mbd} 3$ is also enriched at hydroxymethylated genes and seems to mediate some effects of hydroxymethylation on gene expression in ES cells [78]. Collectively, Mbd3 collaborates with diverse epigenetic factors in gene regulation in ESCs.

In ESCs, NuRD complex subunits Mta1/2 and Gata2a/b, but not $\mathrm{Mbd} 3$, can form a repressive complex with Nanog and Oct4 known as NODE (Nanog and Oct4 associated deacetylase) [11,12,15]. NODE is recruited to Nanog and Oct4 target genes independently of Mbd3. Knock-down of NODE component Mta1 up-regulates endoderm lineage markers and induces differentiation, which is different from the observation upon $\mathrm{Mbd3}$ depletion, yet similar to that of Nanog depletion. This indicates that in ESCs, NODE functions distinctly from the canonical Mbd3-containing NuRD complex. Furthermore, NuRD subunits Mta1/2, Mi2 $\beta$ and RbAP46 were identified as Sall4 interacting proteins, and thus the NuRD complex is implicated in Sall4 transcription repression [81].

\section{CCR4-Not complex}

The CCR4-Not complex is a multi-subunit, multi-functional complex which can regulate gene expression mainly via ubiquitination and deadenylation [82]. The first indication of the role of the CCR4-Not complex in ESC identity was during a genome-wide screen for genes that perturbed ESC pluripotency upon RNAi-mediated knock-down. Cnot3, one of the subunits of the complex, was highlighted as being essential for ESC pluripotency [83]. This was confirmed upon further discovery that in addition to Cnot3, knock-down of Cnot 1 and Cnot2 also induced differentiation [84]. Interestingly, while the collective presence of Cnot1, 2 and 3 are required to prevent differentiation, knock-down of the other subunits of the CCR4-Not complex did not induce any changes, consistent with the observation that only Cnot1, 2 and 3 , and not any of the other subunits were down-regulated during differentiation of ESCs [84]. This may be explained by the fact that Cnot 1 serves as the scaffold of the complex [85], and that Cnot 2 may be required for the binding of Cnot 3 to the rest of the CCR-Not complex [86], creating a functional interaction between these three components.

Interestingly, knock-down of Cnot1, Cnot2 and Cnot3 resulted in trophectodermal differentiation of ESCs [84], resembling the phenotype for Oct4 knock-down [87,88]. Nevertheless, immunoprecipitation experiments indicated there were no binding interactions between Cnot1-3 and Oct4 [84], in agreement with the finding that Cnot3 is integrated into a transcriptional network that includes c-Myc and Zfx, but not Oct4, Nanog or Sox2 [83]. On a similar note, over-expression of Oct 4 did not rescue knock-down of Cnot1, Cnot 2 and Cnot 3 and knockdown of Oct4 or Sox2 did not cause any immediate change in expression levels of Cnot1, Cnot2 and Cnot3 [84]. This strengthened the idea that the CCR4-Not complex acts independent of the Oct4-Sox2-Nanog master regulators. Still, the phenotype observed upon knock-down of either of the Cnot subunits suggests that the complex may repress trophectodermal genes, in accordance with its role in transcriptional repression $[89,90]$. However, the repression of trophectodermal genes may be indirect, given ChIP-chip results showing that Cnot3 does not bind to promoter regions of trophectodermal genes [83]. Thus, it would be of interest to elucidate the mechanism and enzymatic activities by which the CCR4-Not complex regulates ESC identity.

\section{Tri-partite motif-containing protein 28 (TRIM28)}

TRIM28, also known as KAP1 or TIF1 $\beta$, has been identified as a cofactor for KRAB domain-containing zinc finger proteins [91]. Its role in pluripotency was first hinted at when it was detected as a Nanogbinding protein [16]. It was subsequently identified to be essential for pluripotency regulation through RNAi screens [34,83]. TRIM28 also interacts with Oct4 when phosphorylated at serine 824 [92], which was the form previously ascertained to modulate the decondensation of chromatin conformation during DNA damage [93]. This is likely to be due to the recruitment of ATP-dependent chromatin remodelling complexes, in particular the ESC-specific SWI/SNF complex esBAF. This was in turn associated with the expression of pluripotency genes as well as the increased efficiency of pluripotency induction [92].

In contrast to its role as a co-activator above, TRIM28 is essential as a co-repressor for the function of ZFP57 [94], which is required to maintain both maternal and paternal imprints in ESCs [95] and in embryos [96]. This involves the binding of ZFP57 to specific hexanucleotide sequence found at imprinting control regions [97], where it recruits TRIM28 via the KRAB domain [98]. TRIM28 then acts to recruit DNA methyltransferases to maintain the DNA methylation patterns [98] and facilitates the establishment of higher order heterochromatin structure by engaging histone $\mathrm{H} 3 \mathrm{~K} 9$ methyhltranferase SETDB1 and heterochromatin protein $1 \gamma(\mathrm{HP} 1 \gamma)$ to maintain transcriptional silence in an allele-specific manner $[97,99]$. It seems that association with the HP1 family of proteins is required for transcriptional repression facilitated by TRIM28 [100]. There also appears to be a role for histone deacetylation, from the observation that the NuRD complex plays a part in TRIM28 transcriptional repression [101].

TRIM28 is also a cofactor for ZFP809, another KRAB-containing zinc finger protein, and is similar to ZFP57 in its function in repressing the murine leukemia virus (MLV) in ESCs. ZFP809 binds to the primer binding site (PBS) that is required for the transcription of the retrovirus, and subsequently recruits TRIM28 through the KRAB domain $[102,103]$. Given the involvement of ESET in ZFP809-mediated silencing of retroviruses, the mechanism by which retroviruses are repressed may also involve the formation of heterochromatin [104] Other than MLV, TRIM28 also represses other retroviruses, including those that harbour PBS sequences different from MLV, such as visna, spuma, and the Mason-Pfizer monkey virus [105], and endogenous retroviruses (ERVs) that are active in the mammalian genome [106]. However, the transcription factor that recruits TRIM28 in these other instances is not ZFP809 [105], but most likely some other unidentified KRAB domain-containing zinc finger proteins. 


\section{Mediators}

Mediators are multi-subunit complexes which generally act as coactivators in RNAPII transcription. Mediators interact with both DNA-binding transcription factors and RNAPII machinery and form chromatin loops between the enhancers and promoters of active genes $[107,108]$. Recent studies have identified some roles for mediators in the regulation of ES pluripotency. A RNAi screen for regulators necessary for ESC state identified 12 subunits of the Mediator complex, including Med6, Med7, Med10, Med12, Med14, Med15, Med17, Med21, Med24, Med27, Med28, Med30, which are required for Oct4 maintenance in ESCs [109]. ChIP-seq results indicated that mediators contribute to gene regulation in the Oct4-Sox2-Nanog core circuitry, given the evidence that they can associate with promoters of Pou5f1, Nanog and other actively transcribed genes at sites bound by crucial transcription factors of the circuitry $[6,109]$.

Among these subunits, Med12 is essential for early mouse embryogenesis, since its absence causes embryonic arrest at E7.5, with the loss of canonical Wnt/ $\beta$-catenin signaling [110]. Human MED12 mutations cause Lujan-Fryns syndrome and Opitz-Kaveggia syndrome $[111,112]$. In ESCs, Med21 is found to be indispensable for ESC viability and homozygous disruption of Med21 is lethal in ESCs [113]. Med12 knock-down ESCs display phenotypes and gene expression profiles similar to those resulting from Nanog depletion [114]. In addition, Med12 is a Nanog-associated protein and co-occupies Nanog target promoters. Therefore Med12 may facilitate Nanog trans-activation functions in gene regulation [114].

Med15 is essential for the Smad2/3 transcriptional response [115]. As a nuclear partner of TAZ, Med15 retains TAZ in the nucleus and helps to maintain TAZ-mediated nuclear accumulation of Smad and expression of pluripotency markers Pou5f1 and Nanog in hESCs [116].

CDK8, Cyclin C, Med12 and Med13 can form a sub-complex known as the CDK8 sub-module which negatively regulates mediators in the recruitment and activation of RNAPII [117]. The CDK8 submodule can also recruit G9a methyltransferase associated with RIP140 repressive complex, jointly mediating gene inactivation [118]. Recently, an important role of CDK8 in ESCs was revealed, in which CDK8 serves as activator of several signaling pathways, such as the Wnt/ $\beta$-catenin pathway, Notch pathway, and the TGF $/$ BMP signaling pathway, which are key regulators in ESCs [119-122]. CDK8 also maintains ESC pluripotency through the regulation of Myc and Myc target genes [123].

Mediators can also regulate gene transcription through synergizing chromatin remodelers with chromosome conformation modification in ESCs. For instance, mediators are necessary for the recruitment of CHD1, a H3K4me3-associated chromatin remodeler, and therefore facilitates RNAPII transcription initiation of active genes in ESCs [124]. Furthermore, mediators and the Ada-Two-A-containing complex (ATAC) histone acetyltransferase can form a highly stable meta-coactivator complex (MECO), which regulates transcription of RNAPII-transcribed non-coding RNA (ncRNA) genes in ESCs [125].

In summary, there is compelling evidence showing that mediators are required for ESC pluripotency regulation. The underlying mechanisms include regulation of RNAPII, contributing to the ESC-specific transcription circuitries by mediating functions of core transcription factors like Nanog and Myc, facilitating signaling transductions and acting as chromatin remodeler partners.

\section{Cohesin}

The Cohesin complex is composed of four core subunits: Smcla, Smc3, Stag2 and Rad21, and is primarily required for sister chromatid cohesion and chromosome compaction during meiosis and mitosis [126]. Studies in model organisms and evidence that cohesin is associated with developmental abnormalities have extended the role of cohesin to the regulation of gene expression $[127,128]$.

How cohesin contributes to executive gene expression programs is not well understood. ChIP-seq results have shown that cohesin cooccupies the same binding sites as CCCTC-binding factor (CTCF) in mammalian cells and may contribute to CTCF insulator function by stabilizing DNA loop formation [129-131]. Similarly, cohesin is required for estrogen-dependent transcription regulation in breast cancer cells and mediator-activated transcription in ESCs [109,132].

Previous studies have identified the important roles of cohesin in ESC pluripotency regulation. As shown in two different ESC identity RNAi screens, the level of Oct4 is highly sensitive to reduced levels of cohesin subunits and the cohesin loading factor, Nipbl, which loads cohesin onto DNA $[83,109]$. As such, cohesin may bind to promoters of key pluripotency-related genes, including Pou5f1 and Nanog [109]. Furthermore, ChIP-seq results determined co-localization of cohesin with CTCF and mediators in their genomic regions in ESCs [109]. However, there are still nearly one-quarter of cohesin binding sites which are not occupied by either CTCF or mediators, implying that cohesin has other possible partners [109]. Based on what has been found, we may hypothesize that cohesin regulates ESC chromatin architecture through two possible mutually exclusive mechanisms: (i) cohesin can repress gene transcription via CTCF in the same way as in other mammalian cells, or (ii) cohesin can specially interact with mediators at the actively transcribed gene locus, stabilizing the enhancer-core promoter loops brought about by mediators.

Another study found that the loss of RAD21 affects pluripotency and induces differentiation of ESCs. RAD21 co-occupies binding sites bound by pluripotency-associated transcription factors independently of CTCF and is an integral component of the ESC transcriptional network, which is further demonstrated by the observation that the change of gene expression profile upon RAD21 knock-down resembles that upon Nanog depletion [133].

Moreover, cohesin subunits are interacting partners of Oct4 and Nanog-Smcla is identified as an Oct4 interaction protein [12] and Nanog is found to bind to cohesin subunit Stag2 and cohesin complex regulatory protein Wapl, which is necessary for cohesin removal from the chromatin $[16,133]$.

Although cohesin has important roles in maintaining ESC-specific chromatin architecture (via either mediators or CTCF) and mediates ESC-specific gene transcription activation or repression, the molecular mechanism remains to be further elucidated. Besides, considering that cohesin co-localizes with many key transcription factors in ESCs, together with the observed binding interactions of Oct4 with Smcla and Nanog with Stag1 and Wapl, pluripotency transcription factors may mediate the placement of cohesin at CTCF-independent binding sites. For instance, Nanog may recruit cohesin to its binding sites through the interaction with Stag1 and/or Wapl [133]. Conversely, cohesin may also assist these core transcription factors in their functions.

\section{Condensin}

Similar to cohesin, condensin is also a structural maintenance of 
Citation: Ma H, Ow JR, Chen X, Wu Q (2012) With or Without them: Essential Roles of Cofactors in ES Cells. J Stem Cell Res Ther S10:006. doi:10.4172/2157-7633.S10-006

Page 5 of 9

\begin{tabular}{|c|c|c|c|}
\hline Cofactor & Gene Symbol & Functions in ESCs & Reference \\
\hline \multicolumn{4}{|l|}{ Coactivators } \\
\hline \multirow{3}{*}{ FACT complex } & \multirow{2}{*}{ SPT16 } & Oct4-associated protein & {$[11,17]$} \\
\hline & & Recruitment of TBP and TFIIB of transcription pre-initiation complex & [50] \\
\hline & SSRP1 & Oct4-associated protein, and also c-Myc binding partner & {$[11,17,56]$} \\
\hline \multirow{2}{*}{ Yes-YAP-Tead pathway } & \multirow{2}{*}{ YAP } & Maintains ES identity,as OE inhibited ESC differentiation & [39] \\
\hline & & Activates pluripotency genes & [41] \\
\hline \multirow{5}{*}{ DNA repair proteins } & \multirow{2}{*}{ MSH2/MSH6 } & Oct4-associated proteins & {$[11,12,17]$} \\
\hline & & Acts as a "sliding clamp" that disassembles histone & {$[45]$} \\
\hline & \multirow{3}{*}{ XPC-RAD23B-CETN2 } & Located at Oct4 and Nanog promoters & {$[47]$} \\
\hline & & Required for ESC identity and somatic cell reprogramming & {$[47]$} \\
\hline & & Regulates of histone modification to mediate transcription & [48] \\
\hline \multirow{16}{*}{ Mediators } & Med6 & \multirow{9}{*}{ Required for Oct4 maintenance } & \multirow{9}{*}{ [109] } \\
\hline & Med7 & & \\
\hline & Med10 & & \\
\hline & Med14 & & \\
\hline & Med17 & & \\
\hline & Med24 & & \\
\hline & Med27 & & \\
\hline & Med28 & & \\
\hline & Med30 & & \\
\hline & \multirow{2}{*}{ Med12 } & Required for Oct4 maintenance & [109] \\
\hline & & Nanog-associated protein, regulates Nanog and Nanog target genes & [114] \\
\hline & Med15 & Required for Oct4 and Nanog expression in hESCs & {$[109,116]$} \\
\hline & \multirow{2}{*}{ Med21 } & Required for Oct4 maintenance & {$[109]$} \\
\hline & & Required for ESC survival & {$[113]$} \\
\hline & CDK8 & Regulates Myc and Myc target genes & {$[123]$} \\
\hline & MECO & Regulates transcription of ncRNA genes & {$[125]$} \\
\hline \multirow{8}{*}{ Cohesin and associated proteins } & \multirow{2}{*}{ Smc1a } & Oct4-associated protein, & [12] \\
\hline & & Required to maintain ESC identity and viability & {$[133,137]$} \\
\hline & Smc3 & Required to maintain ESC identity & {$[133]$} \\
\hline & Stag2 & Nanog-associated protein & {$[133]$} \\
\hline & \multirow{2}{*}{ Rad21 } & Required to maintain ESC identity & {$[133]$} \\
\hline & & Regulates Nanog and Nanog target genes & {$[16]$} \\
\hline & Nibpl & Required for Oct4 maintenance & [109] \\
\hline & Wapl & Nanog-associated protein & {$[16,133]$} \\
\hline \multirow{2}{*}{ Condensin } & Smc2 & Required for ESC survival & [34] \\
\hline & Smc4 & Involved in interphase high-order chromatin organization & {$[137]$} \\
\hline \multirow{5}{*}{ Histone acetyltrans-ferases (HATs) } & & Component of ESC transcription factor network and modulates Nanog expression & {$[9,21]$} \\
\hline & P300/CBP complex & Cooperates with $\mathrm{CHD} 7$ & [29] \\
\hline & & Involved in ES cell differentiation & {$[22,28]$} \\
\hline & Tin60 $n 400$ & Oct4-associated protein & [12] \\
\hline & 11 pbo-p400 & Cooperates with Nanog or $\mathrm{H} 3 \mathrm{~K} 4 \mathrm{me} 3$ & {$[34]$} \\
\hline Corepressors & & & \\
\hline & Cnot1 & Prevents ESC differentiation, repression of trophectodermal genes & {$[84]$} \\
\hline CCR4-NOT complex & Cnot2 & & \\
\hline CCR4-NOI complex & Cnot3 & Essential for ESC pluripotency for inducing c-Myc and Zfx, independently of Oct4/Nanog/Sox2 & {$[83,84]$} \\
\hline & Cnot3 & Repression of trophectodermal genes & [84] \\
\hline & & Interacts with Nanog and Oct4, essential for ES pluripotency & {$[16,34,83,92]$} \\
\hline & & Chromatin de-condensation by recruitment of chromatin remodelling complexes & [92] \\
\hline KRAB-ZFP-Trim28 & Trim28 & $\begin{array}{l}\text { Co-repressor to ZFP57 for maintenance of genomic imprinting, possibly by recruiting DNA } \\
\text { methyltransferases and HP1 family }\end{array}$ & [97-99] \\
\hline & & $\begin{array}{l}\text { Co-repressor to ZFP809, and other un-identified transcription factors, for repressing retrovirus } \\
\text { expression }\end{array}$ & {$[102-106]$} \\
\hline & $\sin 30$ & Essential for proliferation, viability and genomic integrity of ESCs & {$[34,68]$} \\
\hline & Sin3a & Interact with Sox2 and Nanog, and positively regulates Nanog & {$[15,69]$} \\
\hline & & Essential for derivation of ESCs & [73] \\
\hline Histone deacetyla-ses (HDACs) & & Represses lineage genes to maintain the full pluripotency of ES cells & {$[15,73,75]$} \\
\hline & NuRD complex & Forms a repressive ESC-specific NODE complex together with Oct4 and Nanog & {$[15]$} \\
\hline & & Interacts with other chromatin modifiers to mediate gene regulation & [76-78] \\
\hline & & Implicated in Sall4-mediated transcription repression & [81] \\
\hline
\end{tabular}

Table 1: Known functions of cofactors in ES cells. 
A

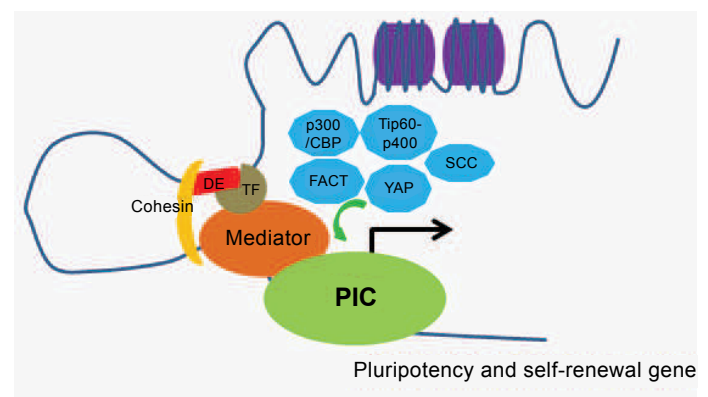

B

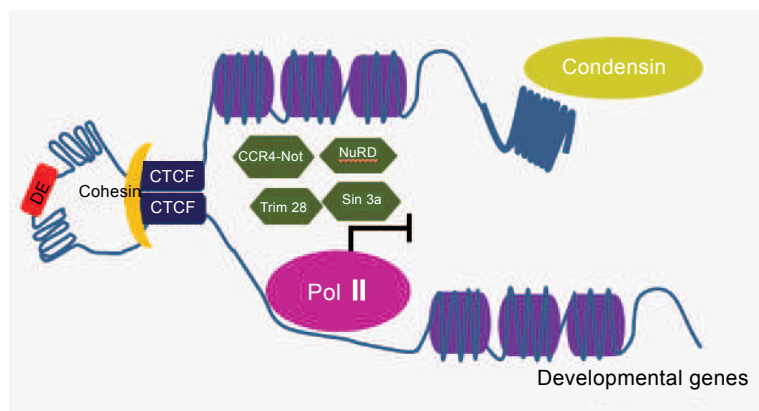

Figure 1: Schematic model of transcriptional regulation by cofactors IN ESCs (A) Transcriptional activation by coactivators, cohesin and mediators. Coactivators p300/CBP complex, Tip60-p400, SCC, YAP, FACT may recruit chromatin remodelers and histone modifiers to open up the chromatin structure. Mediators and cohesin facilitate DNA loop formation to bring the Distal Enhancer (DE) to proximity of the promoter, and the Pre-initiation Complex (PIC) is assembled to initiate transcription. (B) Transcriptional repression by corepressors and condensin. Condensin is required for proper chromatin conformation and epigenetic modifications in ES cells. Cohesin can stabilize the DNA loop formed by the insulator CTCF to avoid interactions between the DE and promoter. Corepressors CCR4-Not, Sin3a, NuRD, Trim28 can recruit HDACs to condensed chromatin and prevent transcription factors from binding to genomic DNA. The RNA polymerase II activity will be suppressed.

chromosomes (SMC) protein complex. It is required for chromosome compaction and meiotic condensation, chromosome segregation and removal of cohesin during cell division [134]. Studies in model organisms have suggested a role of condensin in gene regulation, possibly through repression of RNAPII transcription $[135,136]$.

Condensin has a role in maintaining the specific interphase chromatin structure in ESCs, suggesting that condensin plays a role in transcription regulation. Indeed, knock-down of Smc2 and Smc4, which are core catalytic subunits of mammalian condensin complexes, causes ESC-specific apoptosis [34,137]. Enlarged nuclei, altered higherorder chromatin conformation and epigenetic modification changes were also observed in the knocked-down ESCs, but not in somatic cells [137]. This suggests that ESCs require condensin for their unique chromosome folding, which is different from somatic cells. Thus, there is still much to discover about how condensin functions in transcription and chromosome regulation in ESCs.

\section{Summary and Perspectives}

In summary, cofactors including coactivators, corepressors, mediators, cohesin and condensin that that function through histone modification, chromatin remodeling or the recruitment of transcription machinery, are vital for the regulatory activity of transcription factors (Table 1, Figure 1). Transcription factors are in turn responsible for recruiting the cofactors to their target genes (Figure 1). Many of these cofactors are also present in differentiated cells and serve to play different roles when compared to their function in ESCs. This is likely due to the presence of cell type-specific factors that trigger the cell typespecific roles of these cofactors in different context. Therefore, it would be worthwhile to further determine how the interactome of these proteins leads to their specific functions and how it integrates into their regulation of the transcriptional network in ESCs. In particular, more structural studies on cofactor complexes and combination of genomewide location analysis with computational biology will provide novel insights into cellular functions of cofactors in ES cells.

\section{Acknowledgement}

We thank Eunice Lin and Yun Hwa Lee for critical reading of the manuscript Research in Q. Wu's lab is supported by National University of Singapore (NUS) and Singapore Ministry of Education.

\section{References}

1. Evans MJ, Kaufman MH (1981) Establishment in culture of pluripotential cells from mouse embryos. Nature 292: 154-156.

2. Thomson JA, Itskovitz-Eldor J, Shapiro SS, Waknitz MA, Swiergiel JJ, et al (1998) Embryonic stem cell lines derived from human blastocysts. Science 282: $1145-1147$.

3. Smith AG (2001) Embryo-derived stem cells: of mice and men. Annu Rev Cel Dev Biol 17: 435-462.

4. Keller G (2005) Embryonic stem cell differentiation: emergence of a new era in biology and medicine. Genes Dev 19: 1129-1155.

5. Surani MA, Hayashi K, Hajkova P (2007) Genetic and epigenetic regulators of pluripotency. Cell 128: 747-762

6. Young RA (2011) Control of the embryonic stem cell state. Cell 144: 940-954.

7. Boyer LA, Lee TI, Cole MF, Johnstone SE, Levine SS, et al. (2005) Core transcriptional regulatory circuitry in human embryonic stem cells. Cell 122 947-956.

8. Loh YH, Wu Q, Chew JL, Vega VB, Zhang W, et al. (2006) The Oct4 and Nanog transcription network regulates pluripotency in mouse embryonic stem cells. Nat Genet 38: 431-440.

9. Chen X, Xu H, Yuan P, Fang F, Huss M, et al. (2008) Integration of external signaling pathways with the core transcriptional network in embryonic stem cells. Cell 133: 1106-1117.

10. Kim J, Chu J, Shen X, Wang J, Orkin SH (2008) An extended transcriptional network for pluripotency of embryonic stem cells. Cell 132: 1049-1061.

11. Pardo M, Lang B, Yu L, Prosser H, Bradley A, et al. (2010) An expanded Oct4 interaction network: implications for stem cell biology, development, and disease. Cell Stem Cell 6: 382-395.

12. van den Berg DL, Snoek T, Mullin NP, Yates A, Bezstarosti K, et al. (2010) An Oct4-centered protein interaction network in embryonic stem cells. Cell Stem Cell 6: 369-381.

13. Boyer LA, Plath K, Zeitlinger J, Brambrink T, Medeiros LA, et al. (2006) Polycomb complexes repress developmental regulators in murine embryonic stem cells. Nature 441: 349-353.

14. Lee TI, Jenner RG, Boyer LA, Guenther MG, Levine SS, et al. (2006) Contro of developmental regulators by Polycomb in human embryonic stem cells. Cell 125: 301-313.

15. Liang J, Wan M, Zhang Y, Gu P, Xin H, et al. (2008) Nanog and Oct4 associate with unique transcriptional repression complexes in embryonic stem cells. Nat Cell Biol 10: 731-739.

16. Wang J, Rao S, Chu J, Shen X, Levasseur DN, et al. (2006) A protein interaction network for pluripotency of embryonic stem cells. Nature 444: 364-368.

17. Ding J, Xu H, Faiola F, Ma'ayan A, Wang J (2012) Oct4 links multiple epigenetic pathways to the pluripotency network. Cell Res 22: 155-167.

18. Näär AM, Lemon BD, Tjian R (2001) Transcriptional coactivator complexes Annu Rev Biochem 70: 475-501.

19. Rando OJ, Chang HY (2009) Genome-wide views of chromatin structure. Annu Rev Biochem 78: 245-271. 
Citation: Ma H, Ow JR, Chen X, Wu Q (2012) With or Without them: Essential Roles of Cofactors in ES Cells. J Stem Cell Res Ther S10:006. doi:10.4172/2157-7633.S10-006

Page 7 of 9

20. Goodman RH, Smolik S (2000) CBP/p300 in cell growth, transformation, and development. Genes Dev 14: 1553-1577.

21. Zhong $X$, Jin $Y(2009)$ Critical roles of coactivator p300 in mouse embryonic stem cell differentiation and Nanog expression. J Biol Chem 284: 9168-9175.

22. Kamiya D, Banno S, Sasai N, Ohgushi M, Inomata H, et al. (2011) Intrinsic transition of embryonic stem-cell differentiation into neural progenitors. Nature 470: 503-509.

23. Polesskaya A, Naguibneva I, Fritsch L, Duquet A, Ait-Si-Ali S, et al. (2001) CBP/p300 and muscle differentiation: no HAT, no muscle. EMBO J 20: 68166825.

24. Roth JF, Shikama N, Henzen C, Desbaillets I, Lutz W, et al. (2003) Differential role of p300 and CBP acetyltransferase during myogenesis: p300 acts upstream of MyoD and Myf5. EMBO J 22: 5186-5196.

25. Kawamura T, Ono K, Morimoto T, Wada H, Hirai M, et al. (2005) Acetylation of GATA-4 is involved in the differentiation of embryonic stem cells into cardiac myocytes. J Biol Chem 280: 19682-19688.

26. Hoffmann A, Spengler D (2008) A new coactivator function for Zac1's C2H2 zinc finger DNA-binding domain in selectively controlling PCAF activity. Mol Cell Biol 28: 6078-6093.

27. Chen YL, Monteith N, Law PY, Loh HH (2010) Dynamic association of p300 with the promoter of the $\mathrm{G}$ protein-coupled rat delta opioid receptor gene during NGF-induced neuronal differentiation. Biochem Biophys Res Commun 396 294-298.

28. Miyabayashi T, Teo JL, Yamamoto M, McMillan M, Nguyen C, et al. (2007) Wnt/beta-catenin/CBP signaling maintains long-term murine embryonic stem cell pluripotency. Proc Natl Acad Sci USA 104: 5668-5673.

29. Schnetz MP, Handoko L, Akhtar-Zaidi B, Bartels CF, Pereira CF, et al. (2010) $\mathrm{CHD} 7$ targets active gene enhancer elements to modulate ES cell-specific gene expression. PLoS Genet 6: e1001023.

30. Lessard JA, Crabtree GR (2010) Chromatin regulatory mechanisms in pluripotency. Annu Rev Cell Dev Biol 26: 503-532.

31. Herceg Z, Hulla W, Gell D, Cuenin C, Lleonart M, et al. (2001) Disruption of Trrap causes early embryonic lethality and defects in cell cycle progression. Nat Genet 29: 206-211.

32. Hu Y, Fisher JB, Koprowski S, McAllister D, Kim MS, et al. (2009) Homozygous disruption of the Tip60 gene causes early embryonic lethality. Dev Dyn 238 : 2912-2921.

33. Mohan KN, Ding F, Chaillet JR (2011) Distinct roles of DMAP1 in mouse development. Mol Cell Biol 31: 1861-1869.

34. Fazzio TG, Huff JT, Panning B (2008) An RNAi screen of chromatin proteins identifies Tip60-p400 as a regulator of embryonic stem cell identity. Cell 134 $162-174$

35. Fazzio TG, Huff JT, Panning B (2008) Chromatin regulation Tip(60)s the balance in embryonic stem cell self-renewal. Cell Cycle 7: 3302-3306

36. Sudol M (1994) Yes-associated protein (YAP65) is a proline-rich phosphoprotein that binds to the $\mathrm{SH} 3$ domain of the Yes proto-oncogene product. Oncogene 9: 2145-2152.

37. Yagi R, Kohn MJ, Karavanova I, Kaneko KJ, Vullhorst D, et al. (2007) Transcription factor TEAD4 specifies the trophectoderm lineage at the beginning of mammalian development. Development 134: 3827-3836.

38. Nishioka N, Inoue K, Adachi K, Kiyonari H, Ota M, et al. (2009) The Hippo signaling pathway components Lats and Yap pattern Tead4 activity to distinguish mouse trophectoderm from inner cell mass. Dev Cell 16: 398-410.

39. Lian I, Kim J, Okazawa H, Zhao J, Zhao B, et al. (2010) The role of YAP transcription coactivator in regulating stem cell self-renewal and differentiation. Genes Dev 24: 1106-1118.

40. Annerén C, Cowan CA, Melton DA (2004) The Src family of tyrosine kinases is important for embryonic stem cell self-renewal. J Biol Chem 279: 31590-31598.

41. Tamm C, Böwer N, Annerén C (2011) Regulation of mouse embryonic stem cell self-renewal by a Yes-YAP-TEAD2 signaling pathway downstream of LIF. J Cell Sci 124: 1136-1144.

42. Acharya S, Wilson T, Gradia S, Kane MF, Guerrette S, et al. (1996) hMSH2 forms specific mispair-binding complexes with hMSH3 and hMSH6. Proc Nat Acad Sci USA 93: 13629-13634.

43. Gradia S, Acharya S, Fishel R (1997) The human mismatch recognition complex hMSH2-hMSH6 functions as a novel molecular switch. Cell 91: 9951005.

44. Gradia S, Subramanian D, Wilson T, Acharya S, Makhov A, et al. (1999) hMSH2-hMSH6 forms a hydrolysis-independent sliding clamp on mismatched DNA. Mol Cell 3: 255-261.

45. Javaid S, Manohar M, Punja N, Mooney A, Ottesen JJ, et al. (2009) Nucleosome remodeling by hMSH2-hMSH6. Mol Cell 36: 1086-1094.

46. Johnson RE, Kowali GK, Prakash L, Prakash S (1996) Requirement of the yeast MSH3 and MSH6 genes for MSH2-dependent genomic stability. J Biol Chem 271: 7285-7288.

47. Fong YW, Inouye C, Yamaguchi T, Cattoglio C, Grubisic I, et al. (2011) A DNA repair complex functions as an Oct4/Sox2 coactivator in embryonic stem cells Cell 147: 120-131.

48. Le May N, Mota-Fernandes D, Vélez-Cruz R, Iltis I, Biard D, et al. (2010) NER factors are recruited to active promoters and facilitate chromatin modification for transcription in the absence of exogenous genotoxic attack. Mol Cell 38 54-66.

49. Orphanides G, LeRoy G, Chang CH, Luse DS, Reinberg D (1998) FACT, a factor that facilitates transcript elongation through nucleosomes. Cell 92: 105116

50. Mason PB, Struhl K (2003) The FACT complex travels with elongating RNA polymerase II and is important for the fidelity of transcriptional initiation in vivo. Mol Cell Biol 23: 8323-8333.

51. Belotserkovskaya R, Oh S, Bondarenko VA, Orphanides G, Studitsky VM et al. (2003) FACT facilitates transcription-dependent nucleosome alteration. Science 301: 1090-1093

52. Ransom M, Williams SK, Dechassa ML, Das C, Linger J, et al. (2009) FACT and the proteasome promote promoter chromatin disassembly and transcriptional initiation. J Biol Chem 284: 23461-23471.

53. Takahata S, Yu Y, Stillman DJ (2009) FACT and Asf1 regulate nucleosome dynamics and coactivator binding at the $\mathrm{HO}$ promoter. Mol Cell 34: 405-415.

54. Orphanides G, Wu WH, Lane WS, Hampsey M, Reinberg D (1999) The chromatin-specific transcription elongation factor FACT comprises human SPT16 and SSRP1 proteins. Nature 400: 284-288.

55. Cao S, Bendall H, Hicks GG, Nashabi A, Sakano H, et al. (2003) The highmobility-group box protein SSRP1/T160 is essential for cell viability in day 3.5 mouse embryos. Mol Cell Biol 23: 5301-5307.

56. Bunker CA, Kingston RE (1995) Identification of a cDNA for SSRP1, an HMGbox protein, by interaction with the c-Myc oncoprotein in a novel bacterial expression screen. Nucleic Acids Res 23: 269-276.

57. Knoepfler PS (2008) Why myc? An unexpected ingredient in the stem cel cocktail. Cell Stem Cell 2: 18-21.

58. Smith KN, Singh AM, Dalton S (2010) Myc represses primitive endoderm differentiation in pluripotent stem cells. Cell Stem Cell 7: 343-354.

59. Schreiber-Agus N, Chin L, Chen K, Torres R, Rao G, et al. (1995) An aminoterminal domain of Mxi1 mediates anti-Myc oncogenic activity and interacts with a homolog of the yeast transcriptional repressor SIN3. Cell 80: 777-786.

60. David G, Alland L, Hong SH, Wong CW, DePinho RA, et al. (1998) Histone deacetylase associated with $\mathrm{mSin} 3 \mathrm{~A}$ mediates repression by the acute promyelocytic leukemia-associated PLZF protein. Oncogene 16: 2549-2556.

61. Huang S, Brandt SJ (2000) mSin3A regulates murine erythroleukemia cell differentiation through association with the TAL1 (or $\mathrm{SCL}$ ) transcription factor. Mol Cell Biol 20: 2248-2259.

62. Le Guezennec X, Vermeulen M, Stunnenberg HG (2006) Molecula characterization of Sin3 PAH-domain interactor specificity and identification of PAH partners. Nucleic Acids Res 34: 3929-3937.

63. Lu P, Hankel IL, Hostager BS, Swartzendruber JA, Friedman AD, et al. (2011) The developmental regulator protein Gon4l associates with protein YY1, corepressor Sin3a, and histone deacetylase 1 and mediates transcriptional repression. J Biol Chem 286: 18311-18319. 
Citation: Ma H, Ow JR, Chen X, Wu Q (2012) With or Without them: Essential Roles of Cofactors in ES Cells. J Stem Cell Res Ther S10:006. doi:10.4172/2157-7633.S10-006

Page 8 of 9

64. Cowley SM, Iritani BM, Mendrysa SM, Xu T, Cheng PF, et al. (2005) The mSin3A chromatin-modifying complex is essential for embryogenesis and T-cell development. Mol Cell Biol 25: 6990-7004.

65. Dannenberg JH, David G, Zhong S, van der Torre J, Wong WH, et al. (2005) $\mathrm{mSin} 3 \mathrm{~A}$ corepressor regulates diverse transcriptional networks governing normal and neoplastic growth and survival. Genes Dev 19: 1581-1595

66. Payne CJ, Gallagher SJ, Foreman O, Dannenberg JH, Depinho RA, et al. (2010) Sin3a is required by sertoli cells to establish a niche for undifferentiated spermatogonia, germ cell tumors, and spermatid elongation. Stem Cells 28 : 1424-1434.

67. McDonel P, Costello I, Hendrich B (2009) Keeping things quiet: roles of NuRD and $\operatorname{Sin} 3$ co-repressor complexes during mammalian development. Int $J$ Biochem Cell Biol 41: 108-116.

68. McDonel P, Demmers J, Tan DW, Watt F, Hendrich BD (2012) Sin3a is essential for the genome integrity and viability of pluripotent cells. Dev Biol 363: 62-73.

69. Baltus GA, Kowalski MP, Tutter AV, Kadam S (2009) A positive regulatory role for the mSin3A-HDAC complex in pluripotency through Nanog and Sox2. J Biol Chem 284: 6998-7006.

70. De Nadal E, Zapater M, Alepuz PM, Sumoy L, Mas G, et al. (2004) The MAPK Hog1 recruits Rpd3 histone deacetylase to activate osmoresponsive genes. Nature 427: 370-374.

71. Denslow SA, Wade PA (2007) The human Mi-2/NuRD complex and gene regulation. Oncogene 26: 5433-5438.

72. Hendrich B, Guy J, Ramsahoye B, Wilson VA, Bird A (2001) Closely related proteins MBD2 and MBD3 play distinctive but interacting roles in mouse development. Genes Dev 15: 710-723.

73. Kaji K, Nichols J, Hendrich B (2007) Mbd3, a component of the NuRD co-repressor complex, is required for development of pluripotent cells. Development 134: 1123-1132.

74. Kaji K, Caballero IM, MacLeod R, Nichols J, Wilson VA, et al. (2006) The NuRD component Mbd3 is required for pluripotency of embryonic stem cells. Nat Cell Biol 8: 285-292.

75. Zhu D, Fang J, Li Y, Zhang J (2009) Mbd3, a component of NuRD/Mi-2 complex, helps maintain pluripotency of mouse embryonic stem cells by repressing trophectoderm differentiation. PLoS ONE 4: e7684.

76. Reynolds N, Latos P, Hynes-Allen A, Loos R, Leaford D, et al. (2012) NuRD suppresses pluripotency gene expression to promote transcriptional heterogeneity and lineage commitment. Cell Stem Cell 10: 583-594.

77. Ho L, Ronan JL, Wu J, Staahl BT, Chen L, et al. (2009) An embryonic stem cell chromatin remodeling complex, esBAF, is essential for embryonic stem cell self-renewal and pluripotency. Proc Natl Acad Sci USA 106: 5181-5186.

78. Yildirim O, Li R, Hung JH, Chen PB, Dong X, et al. (2011) Mbd3/NURD complex regulates expression of 5-hydroxymethylcytosine marked genes in embryonic stem cells. Cell 147: 1498-1510.

79. Unhavaithaya $\mathrm{Y}$, Shin TH, Miliaras N, Lee J, Oyama T, et al. (2002) MEP-1 and a homolog of the NURD complex component Mi-2 act together to maintain germline-soma distinctions in C. elegans. Cell 111: 991-1002.

80. Morey L, Brenner C, Fazi F, Villa R, Gutierrez A, et al. (2008) MBD3, a component of the NuRD complex, facilitates chromatin alteration and deposition of epigenetic marks. Mol Cell Biol 28: 5912-5923.

81. Lu J, Jeong HW, Kong N, Yang Y, Carroll J, et al. (2009) Stem cell factor SALL4 represses the transcriptions of PTEN and SALL1 through an epigenetic repressor complex. PLoS ONE 4: e5577.

82. Collart MA, Panasenko OO (2012) The Ccr4-not complex. Gene 492: 42-53.

83. Hu G, Kim J, Xu Q, Leng Y, Orkin SH, et al. (2009) A genome-wide RNAi screen identifies a new transcriptional module required for self-renewal. Genes Dev 23: 837-848

84. Zheng X, Dumitru R, Lackford BL, Freudenberg JM, Singh AP, et al. (2012) Cnot1, Cnot2, and Cnot3 maintain mouse and human ESC identity and inhibit extraembryonic differentiation. Stem Cells 30: 910-922.

85. Maillet L, Tu C, Hong YK, Shuster EO, Collart MA (2000) The essential function of Not1 lies within the Ccr4-Not complex. J Mol Biol 303: 131-143.
86. Russell P, Benson JD, Denis CL (2002) Characterization of mutations in NOT2 indicates that it plays an important role in maintaining the integrity of the CCR4NOT complex. J Mol Biol 322: 27-39.

87. Nichols J, Zevnik B, Anastassiadis K, Niwa H, Klewe-Nebenius D, et al. (1998) Formation of pluripotent stem cells in the mammalian embryo depends on the POU transcription factor Oct4. Cell 95: 379-391.

88. Niwa H, Miyazaki J, Smith AG (2000) Quantitative expression of Oct-3/4 defines differentiation, dedifferentiation or self-renewal of ES cells. Nat Genet 24: 372-376.

89. Collart MA, Struhl K (1994) NOT1(CDC39), NOT2(CDC36), NOT3, and NOT4 encode a global-negative regulator of transcription that differentially affects TATA-element utilization. Genes Dev 8: 525-537.

90. Zwartjes CG, Jayne S, van den Berg DL, Timmers HT (2004) Repression of promoter activity by CNOT2, a subunit of the transcription regulatory Ccr4-not complex. J Biol Chem 279: 10848-10854.

91. Friedman JR, Fredericks WJ, Jensen DE, Speicher DW, Huang XP, et al. (1996) KAP-1, a novel corepressor for the highly conserved KRAB repression domain. Genes Dev 10: 2067-2078.

92. Seki $Y$, Kurisaki A, Watanabe-Susaki K, Nakajima $Y$, Nakanishi $M$, et al. (2010) TIF1beta regulates the pluripotency of embryonic stem cells in a phosphorylation-dependent manner. Proc Natl Acad Sci USA 107: 1092610931.

93. Ziv Y, Bielopolski D, Galanty Y, Lukas C, Taya Y, et al. (2006) Chromatin relaxation in response to DNA double-strand breaks is modulated by a novel ATM- and KAP-1 dependent pathway. Nat Cell Biol 8: 870-876.

94. Groner AC, Meylan S, Ciuffi A, Zangger N, Ambrosini G, et al. (2010) KRAB-zinc finger proteins and KAP1 can mediate long-range transcriptional repression through heterochromatin spreading. PLoS Genet 6: e1000869.

95. Li X, Ito M, Zhou F, Youngson N, Zuo X, et al. (2008) A maternal-zygotic effect gene, Zfp57, maintains both maternal and paternal imprints. Dev Cell 15: 547 557.

96. Messerschmidt DM, de Vries W, Ito M, Solter D, Ferguson-Smith A, et al (2012) Trim28 is required for epigenetic stability during mouse oocyte to embryo transition. Science 335: 1499-1502.

97. Quenneville S, Verde G, Corsinotti A, Kapopoulou A, Jakobsson J, et al. (2011) In embryonic stem cells, ZFP57/KAP1 recognize a methylated hexanucleotide to affect chromatin and DNA methylation of imprinting control regions. Mol Cell 44: $361-372$

98. Zuo X, Sheng J, Lau HT, McDonald CM, Andrade M, et al. (2012) Zinc finge protein ZFP57 requires its co-factor to recruit DNA methyltransferases and maintains DNA methylation imprint in embryonic stem cells via its transcriptional repression domain. J Biol Chem 287: 2107-2118.

99. Schultz DC, Ayyanathan K, Negorev D, Maul GG, Rauscher FJ 3rd (2002) SETDB1: a novel KAP-1-associated histone H3, lysine 9-specific methyltransferase that contributes to HP1-mediated silencing of euchromatic genes by KRAB zinc-finger proteins. Genes Dev 16: 919-932.

100. Sripathy SP, Stevens J, Schultz DC (2006) The KAP1 corepressor functions to coordinate the assembly of de novo HP1-demarcated microenvironments of heterochromatin required for KRAB zinc finger protein-mediated transcriptional repression. Mol Cell Biol 26: 8623-8638.

101. Schultz DC, Friedman JR, Rauscher FJ 3rd (2001) Targeting histone deacetylase complexes via KRAB-zinc finger proteins: the PHD and bromodomains of KAP-1 form a cooperative unit that recruits a novel isoform of the Mi-2alpha subunit of NuRD. Genes Dev 15: 428-443.

102. Wolf D, Goff SP (2007) TRIM28 mediates primer binding site-targeted silencing of murine leukemia virus in embryonic cells. Cell 131: 46-57.

103. Wolf D, Goff SP (2009) Embryonic stem cells use ZFP809 to silence retroviral DNAs. Nature 458: 1201-1204.

104. Matsui T, Leung D, Miyashita H, Maksakova IA, Miyachi H, et al. (2010) Proviral silencing in embryonic stem cells requires the histone methyltransferase ESET. Nature 464: 927-931.

105. Wolf D, Hug K, Goff SP (2008) TRIM28 mediates primer binding site-targeted silencing of Lys 1,2 tRNA-utilizing retroviruses in embryonic cells. Proc Nat Acad Sci USA 105: 12521-12526.

106. Rowe HM, Jakobsson J, Mesnard D, Rougemont J, Reynard S, et al. (2010) 
Citation: Ma H, Ow JR, Chen X, Wu Q (2012) With or Without them: Essential Roles of Cofactors in ES Cells. J Stem Cell Res Ther S10:006. doi:10.4172/2157-7633.S10-006

KAP1 controls endogenous retroviruses in embryonic stem cells. Nature 463 : 237-240.

107. Malik S, Roeder RG (2005) Dynamic regulation of pol II transcription by the mammalian Mediator complex. Trends Biochem Sci 30: 256-263.

108. Taatjes DJ (2010) The human Mediator complex: a versatile, genome-wide regulator of transcription. Trends Biochem Sci 35: 315-322.

109. Kagey MH, Newman JJ, Bilodeau S, Zhan Y, Orlando DA, et al. (2010) Mediator and cohesin connect gene expression and chromatin architecture. Nature 467: 430-435.

110. Rocha PP, Scholze M, Bleiss W, Schrewe H (2010) Med12 is essential for early mouse development and for canonical Wnt and Wnt/PCP signaling. Development 137: 2723-2731.

111. Schwartz CE, Tarpey PS, Lubs HA, Verloes A, May MM, et al. (2007) The original Lujan syndrome family has a novel missense mutation (p.N1007S) in the MED12 gene. J Med Genet 44: 472-477.

112. Rump P, Niessen RC, Verbruggen KT, Brouwer OF, de Raad M, et al. (2011) A novel mutation in MED12 causes FG syndrome (Opitz-Kaveggia syndrome). Clin Genet 79: 183-188.

113. Tudor M, Murray PJ, Onufryk C, Jaenisch R, Young RA (1999) Ubiquitous expression and embryonic requirement for RNA polymerase II coactivator subunit Srb7 in mice. Genes Dev 13: 2365-2368.

114. Tutter AV, Kowalski MP, Baltus GA, lourgenko V, Labow M, et al. (2009) Role for Med12 in regulation of Nanog and Nanog target genes. J Biol Chem 284 : 3709-3718.

115. Pandur P, Läsche M, Eisenberg LM, Kühl M (2002) Wnt-11 activation of a non-canonical Wnt signalling pathway is required for cardiogenesis. Nature 418: 636-641.

116. Varelas X, Sakuma R, Samavarchi-Tehrani $P$, Peerani R, Rao BM, et al. (2008) TAZ controls Smad nucleocytoplasmic shuttling and regulates human embryonic stem-cell self-renewal. Nat Cell Biol 10: 837-848.

117. Knuesel MT, Meyer KD, Bernecky C, Taatjes DJ (2009) The human CDK8 subcomplex is a molecular switch that controls Mediator coactivator function. Genes Dev 23: 439-451.

118. Persaud SD, Huang WH, Park SW, Wei LN (2011) Gene repressive activity of RIP140 through direct interaction with CDK8. Mol Endocrinol 25: 1689-1698.

119. Fryer CJ, White JB, Jones KA (2004) Mastermind recruits CycC: CDK8 to phosphorylate the Notch ICD and coordinate activation with turnover. Mol Cell 16: 509-520.

120. Firestein R, Bass AJ, Kim SY, Dunn IF, Silver SJ, et al. (2008) CDK8 is a colorectal cancer oncogene that regulates beta-catenin activity. Nature 455 : 547-551.

121. Morris EJ, Ji JY, Yang F, Di Stefano L, Herr A, et al. (2008) E2F1 represses beta-catenin transcription and is antagonized by both pRB and CDK8. Nature 455: 552-556.
122. Alarcón C, Zaromytidou Al, Xi Q, Gao S, Yu J, et al. (2009) Nuclear CDKs drive Smad transcriptional activation and turnover in BMP and TGF-beta pathways. Cell 139: 757-769.

123. Adler AS, McCleland ML, Truong T, Lau S, Modrusan Z, et al. (2012) CDK8 maintains tumor dedifferentiation and embryonic stem cell pluripotency. Cancer Res 72: 2129-2139.

124. Lin JJ, Lehmann LW, Bonora G, Sridharan R, Vashisht AA, et al. (2011) Mediator coordinates PIC assembly with recruitment of CHD1. Genes Dev 25: 2198-2209.

125. Krebs AR, Demmers J, Karmodiya K, Chang NC, Chang AC, et al. (2010) ATAC and Mediator coactivators form a stable complex and regulate a set of non-coding RNA genes. EMBO Rep 11: 541-547.

126. Nasmyth K (2011) Cohesin: a catenase with separate entry and exit gates? Nat Cell Biol 13: 1170-1177.

127.Peric-Hupkes D, van Steensel B (2008) Linking cohesin to gene regulation. Cell 132: 925-928

128. Wendt KS, Peters JM (2009) How cohesin and CTCF cooperate in regulating gene expression. Chromosome Res 17: 201-214.

129. Rubio ED, Reiss DJ, Welcsh PL, Disteche CM, Filippova GN, et al. (2008) CTCF physically links cohesin to chromatin. Proc Natl Acad Sci USA 105 8309-8314.

130. Wendt KS, Yoshida K, Itoh T, Bando M, Koch B, et al. (2008) Cohesin mediates transcriptional insulation by CCCTC-binding factor. Nature 451: 796-801.

131. Chien R, Zeng W, Kawauchi S, Bender MA, Santos R, et al. (2011) Cohesin mediates chromatin interactions that regulate mammalian $\beta$-globin expression. J Biol Chem 286: 17870-17878.

132. Schmidt D, Schwalie PC, Ross-Innes CS, Hurtado A, Brown GD, et al. (2010) A CTCF-independent role for cohesin in tissue-specific transcription. Genome Res 20: 578-588.

133. Nitzsche A, Paszkowski-Rogacz M, Matarese F, Janssen-Megens EM, Hubne NC, et al. (2011) RAD21 cooperates with pluripotency transcription factors in the maintenance of embryonic stem cell identity. PLoS ONE 6: e19470.

134. Cuylen S, Haering $\mathrm{CH}$ (2011) Deciphering condensin action during chromosome segregation. Trends Cell Biol 21: 552-559.

135. Cobbe N, Savvidou E, Heck MM (2006) Diverse mitotic and interphase functions of condensins in Drosophila. Genetics 172: 991-1008.

136. Wood AJ, Severson AF, Meyer BJ (2010) Condensin and cohesin complexity: the expanding repertoire of functions. Nat Rev Genet 11: 391-404.

137. Fazzio TG, Panning B (2010) Condensin complexes regulate mitotic progression and interphase chromatin structure in embryonic stem cells. J Cell Biol 188: 491-503.
This article was originally published in a special issue, Embryonic and Induced Pluripotent Stem Cells handled by Editor(s). Dr. Jianlong Wang, Mount Sinai School of Medicine, United States 